\title{
Carcinoma espinocelular da base do chifre, bilateral e simétrico, em vaca com distúrbio hormonal - relato de caso
}

[Horn-based squamous cell carcinoma, bilateral and symmetrical in cow with hormonal disorder - case report]

\author{
S.A. Caldas $^{1}$, J.H.S. Conceiçãao ${ }^{2}$, L.A. Brust ${ }^{3}$, T. Venuto ${ }^{4}$, S.Z.R. Costa ${ }^{5}$ \\ J.F. Rocha ${ }^{6}$, A.M. Santos ${ }^{7}$, P.V. Peixoto ${ }^{8}$
}

${ }^{1}$ Instituto de Veterinária - Universidade Federal Rural do Rio de Janeiro - Seropédica, RJ

${ }^{2}$ Médico veterinário - Centro de Ensino Superior de Valença - Valença, RJ

${ }^{3}$ Faculdade de Medicina Veterinária de Valença - Centro de Ensino Superior de Valença - Valença, RJ

${ }^{4}$ Autônomo - Valença, RJ

${ }^{5}$ Instituto Federal Farroupilha - Frederico Westphalen, RS

${ }^{6}$ Aluna de pós-graduação - Universidade Federal Rural do Rio de Janeiro - Seropédica, RJ

${ }^{7}$ Autônomo - Nova Iguaçu, RJ

${ }^{8}$ Universidade Federal Rural do Rio de Janeiro - Seropédica, RJ

\section{RESUMO}

Este trabalho tem por objetivo descrever um caso de carcinoma espinocelular da base do chifre, bilateral e simétrico, em uma vaca e discutir a questão hormonal, possivelmente envolvida na patogênese da doença. Tratava-se de uma fêmea bovina, 11 anos, com histórico de emagrecimento progressivo, presença de massas exofíticas na base de ambos os chifres e em anestro por muitos anos. Foi realizada biopsia incisional de ambas as lesões para exame histopatológico e dosagens hormonais. Devido à progressão do quadro clínico, optou-se pela eutanásia, seguida dos exames necroscópico e histopatológico. O exame histopatológico revelou tratar-se de um carcinoma espinocelular infiltrativo bem diferenciado, e as dosagens hormonais apresentaram alterações nos níveis do hormônio luteinizante, folículo estimulante e estrógenos totais. Apesar de existirem descrições de carcinomas espinocelulares da base do chifre, ainda não havia relatos da ocorrência do mesmo bilateral e em uma vaca com distúrbios hormonais.

Palavras-chave: bovino, neoplasia do processo cornual, anestro

\begin{abstract}
The objective of this study was to describe a case of bilateral and symmetrical squamous cell carcinoma from the horn base in a cow and to discuss the hormonal question, possibly involved in its pathogenesis. A 11-year-old beef cow presenting a history of progressive thinning, presence of exophytic masses at the base of both horns and anestrous for many years was assisted. An incisional biopsy of both lesions was performed for histopathological examination and hormonal dosages. Due to the clinical progression, euthanasia followed by necroscopic and histopathological examination was carried out. Histopathological examination revealed a well differentiated infiltrative squamous cell carcinoma and the hormonal dosages presented changes in luteinizing hormone, follicle stimulating and total estrogen levels. Although there are descriptions of basal squamous cell carcinoma of the horn, there were still no reports of the occurrence of the same bilateral in a cow with hormonal disorders.
\end{abstract}

Keywords: bovine, neoplasm of the cornual process, anestrous

\section{INTRODUÇÃO}

Carcinoma espinocelular da base do chifre, neoplasia que afeta quase só bovinos machos castrados, excepcionalmente pode ser observado em vacas e touros. Essa neoplasia tem grande importância na Índia, onde cerca de $1 \%$ da população bovina é afetada, do que resulta significativa perda econômica (Kulkarni, 1953; Zubaidy, 1976). No Brasil, ocorre 
infrequentemente em zebuínos e tem sido descrita nos estados de Minas Gerais (Nascimento et al., 1975), São Paulo (Rezende e Neves, 1975), Mato Grosso do Sul (Lemos et al., 1998), Paraná (Gomes et al., 2012), Paraíba (Firmino et al., 2017) e Bahia (Fernandes et al., 2017). O tumor aparece, em geral, unilateralmente, na base de um dos chifres (Kulkarni, 1953). A patogênese dessa neoplasia ainda não foi elucidada, embora diversos fatores, tais como predisposição genética, trauma constante, vernizes e tintas usadas na pintura dos chifres, radiação solar, desequilíbrio hormonal, indução por vírus ou uma combinação desses fatores, venham sendo sugeridos como associados à condição (Naik et al., 1970). O presente trabalho tem por objetivo descrever um caso de carcinoma espinocelular da base do chifre, bilateral e simétrico, em uma vaca e discutir a questão hormonal envolvida na patogênese da doença.

Uma vaca Nelore, com 11 anos de idade, foi levada ao Hospital Veterinário da Universidade de Valença, estado do Rio de Janeiro, apresentando emagrecimento progressivo, durante seis meses, e massas exofíticas na base de ambos os chifres. Pelo histórico, com a evolução das lesões, os chifres tornaram-se progressivamente frouxos, a ponto de terem sido removidos manualmente. Essa vaca teve apenas uma cria durante a vida e depois entrou em anestro. Inicialmente foi realizada biopsia incisional de ambas as lesões para exame histopatológico e colhido soro para dosagens hormonais. Devido à progressão do quadro clínico, foi realizada a eutanásia, seguida do exame necroscópico e da colheita de fragmentos de todos os órgãos em formalina tamponada a $10 \%$.

Macroscopicamente, observaram-se grandes massas exofíticas, bilaterais e simétricas, com cerca de $20 \mathrm{~cm}$ de diâmetro cada, localmente invasivas na base dos chifres (Fig. 1). A superfície do processo neoplásico era irregular, ulcerada e recoberta por exsudato serossanguinolento e por substância enegrecida (Unguento Friezol ${ }^{\circledR}$ Laboratório Pinus - Brasil) (Fig. 2). Ambas as lesões eram de consistência firme e, ao corte, revelavam superfície seca e dois padrões de coloração, entremeados: amarelo-palha e brancacenta. Havia profunda infiltração bilateral e preenchimento dos seios cornuais, atingindo parte dos frontais. Não havia delimitação evidente ou cápsula perceptível (Fig. 3). A hipófise estava moderadamente aumentada de volume $(2 \mathrm{~cm} \mathrm{x}$ $1,5 \mathrm{~cm})$ e, ao corte, evidenciava pequena formação cística com aproximadamente $1 \mathrm{~cm}$ em seu maior diâmetro; os ovários apresentavam entre seis e oito folículos visíveis cada um.

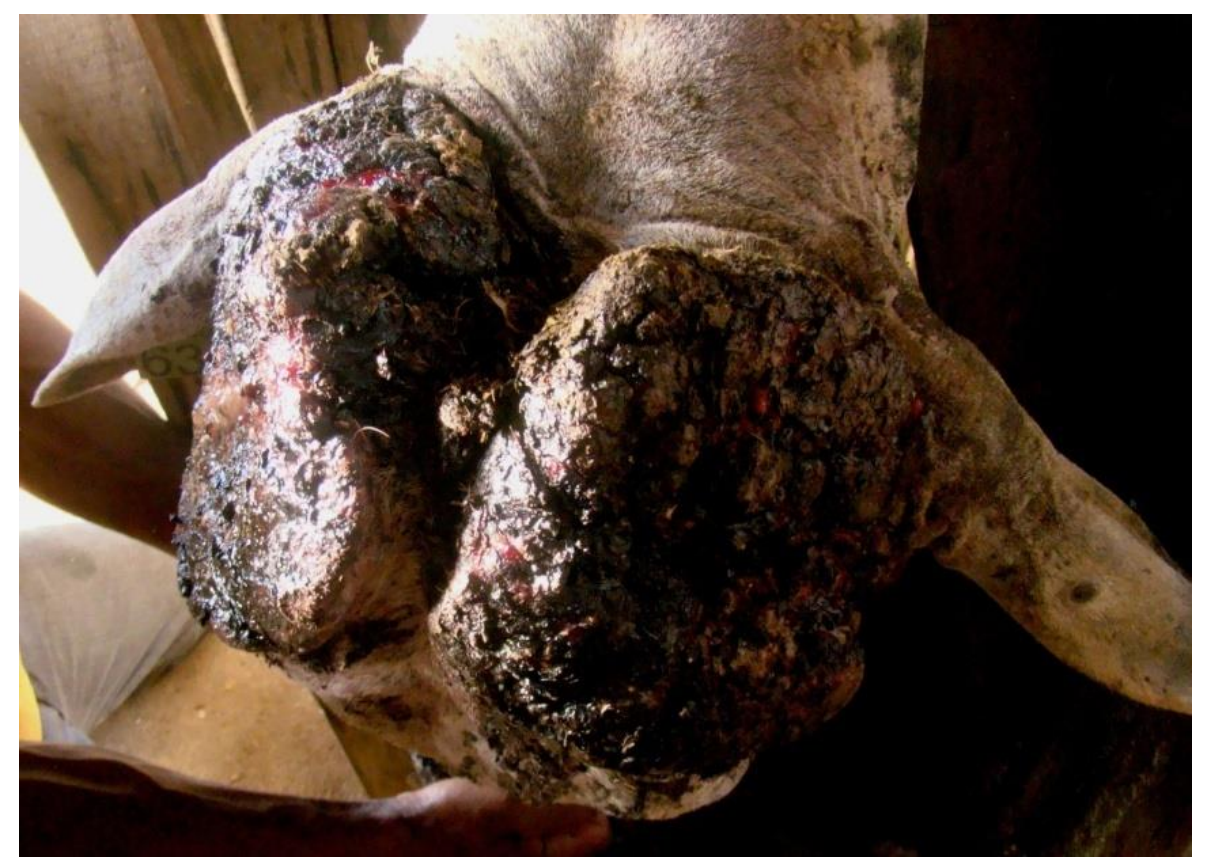

Figura 1. Carcinoma espinocelular da base do chifre em uma vaca. Grandes massas exofíticas, bilaterais e simétricas na base dos chifres. 


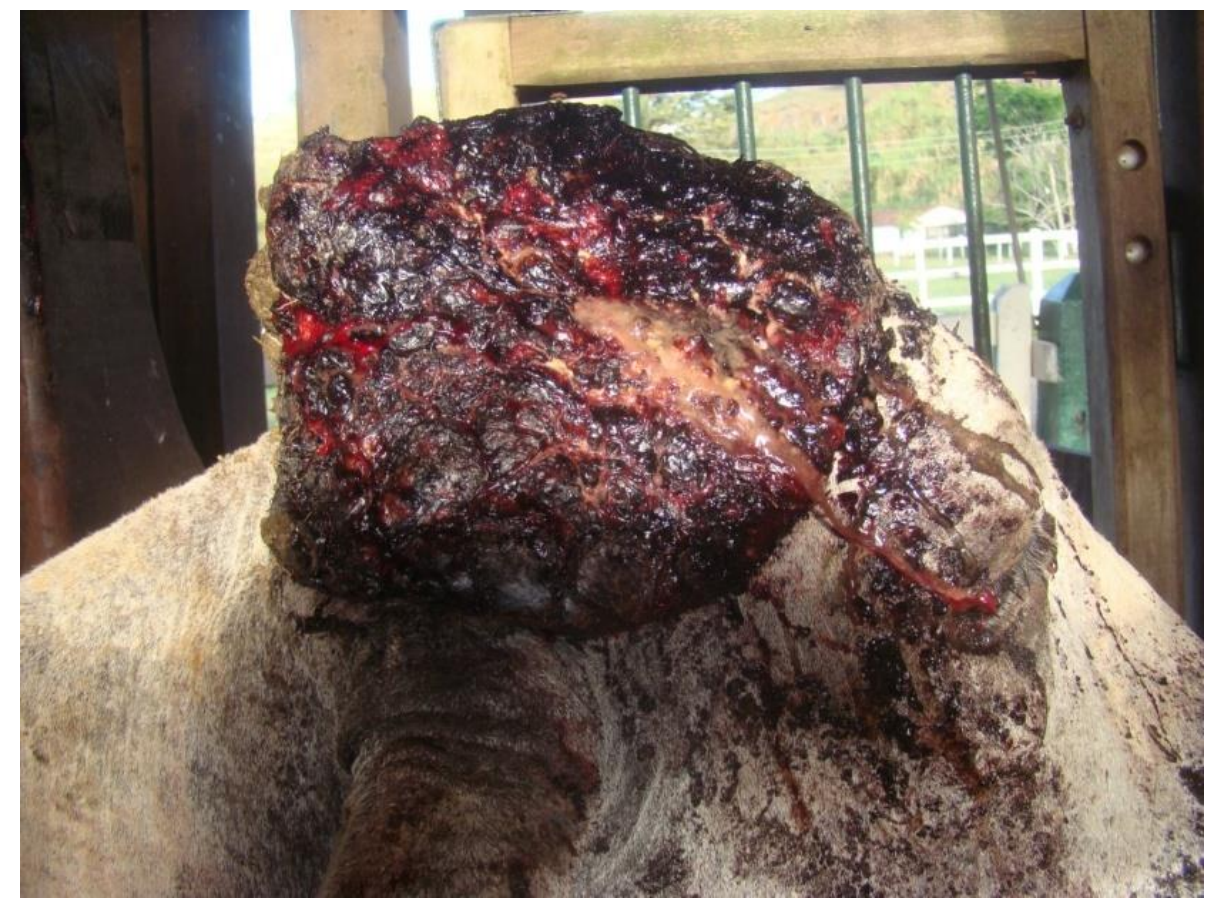

Figura 2. Carcinoma espinocelular da base do chifre em uma vaca. Superfície do processo neoplásico irregular, ulcerada e recoberta por exsudato serossanguinolento e por substância enegrecida (Unguento Friezol $^{\circledR}$ - Laboratório Pinus - Brasil). Vista lateral do tumor.

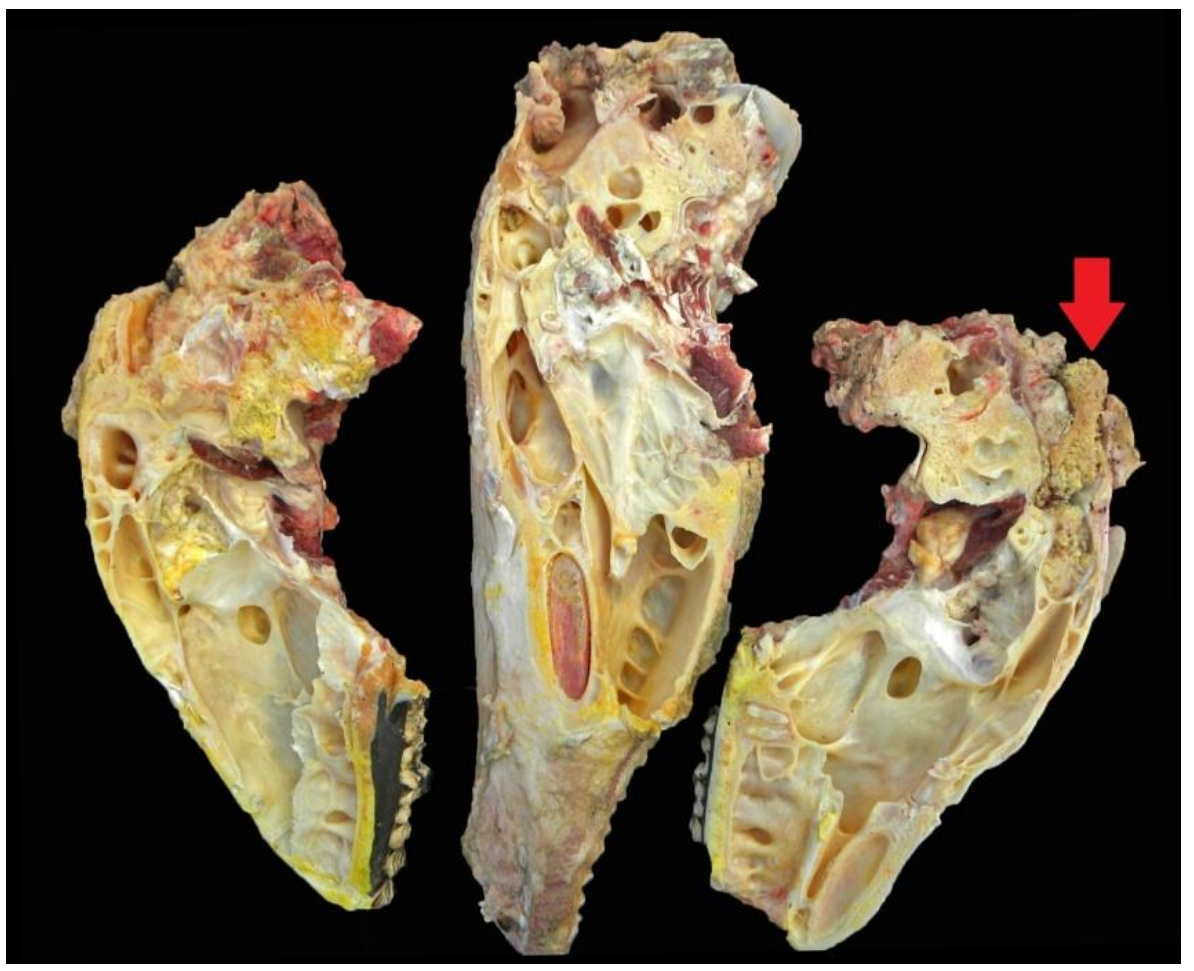

Figura 3. Carcinoma espinocelular da base do chifre em uma vaca. Secções longitudinais da cabeça mostrando superfície seca e dois padrões de coloração, entremeados: amarelo-palha e brancacenta. Invasão do seio frontal pelo tumor (seta). 
O exame histológico - Os cortes histológicos evidenciaram densa proliferação celular neoplásica não encapsulada, que se estendia a partir da epiderme e invadia o tecido subepitelial em direção a todas as bordas, composta por células poligonais arranjadas em grandes ilhas e trabéculas que se anastomosavam, entremeadas por um estroma fibroso moderadamente denso. As células neoplásicas apresentavam bordas variavelmente definidas, com moderada quantidade de citoplasma eosinofílico, núcleo redondo ou oval com cromatina grosseiramente aglomerada e até três nucléolos evidentes. No centro das ilhas e trabéculas, por vezes, havia lamelas de queratina organizadas concentricamente (pérolas de queratina) (Fig. 4). Inúmeros neutrófilos, eosinófilos, linfócitos e plasmócitos infiltravam, de forma difusa, o estroma da neoplasia. O epitélio estava difusamente ulcerado e recoberto por crosta serocelular.

Na adeno-hipófise, havia formação de um grande cisto contendo secreção homogênea eosinofílica, além de moderada hiperplasia das células cromófobas; no ovário, observaram-se numerosos folículos de Graaf e corpus albicans, além de hialinização da parede das artérias. O resultado das dosagens hormonais revelou significativo aumento nos níveis de hormônio luteinizante $(6,9 \mathrm{ng} / \mathrm{mL})$ e leve elevação dos níveis de hormônio folículo estimulante $(12,1 \mathrm{ng} / \mathrm{mL})$, bem como marcada queda nos níveis de estrógenos totais $(0,98 \mathrm{pg} / \mathrm{mL})$; a progesterona situou-se em $0,53 \mathrm{ng} / \mathrm{mL}$ de soro.

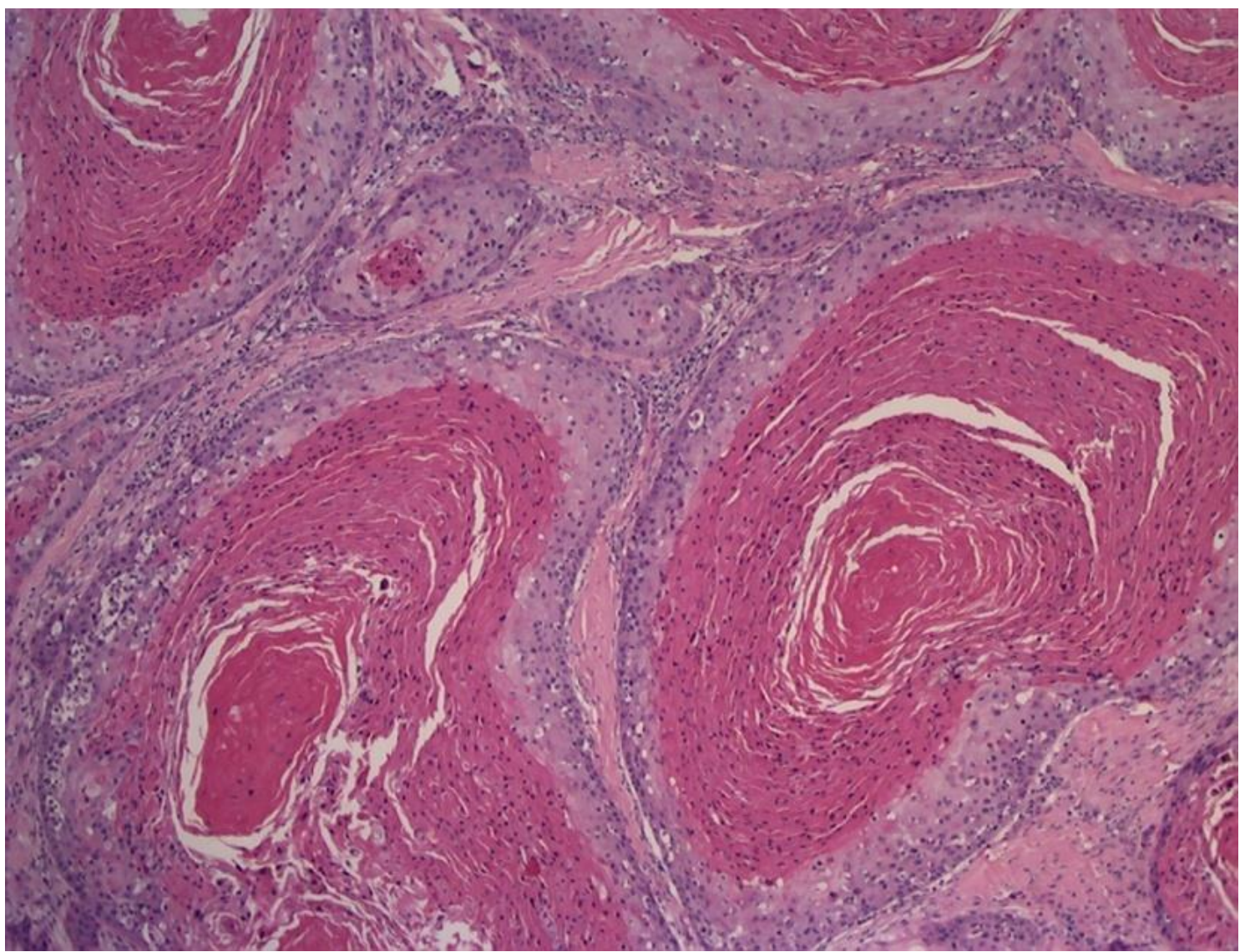

Figura 4. Fotomicrografia do carcinoma espinocelular da base do chifre em uma vaca. Proliferação de células epiteliais neoplásicas, arranjadas em ilhas e cordões, entremeadas por moderado estroma fibroso. Ao centro das ilhas, há intensa deposição de lamelas concêntricas de queratina (pérolas). Obj. 10x, HE. 


\section{DISCUSSÃO}

Neste estudo, descreve-se a ocorrência de um carcinoma espinocelular bilateral, simétrico, da base do chifre, em uma vaca adulta. Carcinomas espinocelular da base do chifre (CEBC) são muito comuns na Índia (Kulkarni, 1953; Zubaidy, 1976), mas no Brasil, ao que tudo indica, são bem pouco frequentes (Nascimento et al., 1975; Rezende e Neves, 1975; Lemos et al., 1998; Gomes et al., 2012; Fernandes et al., 2017; Firmino et al., 2017). Entre os diversos fatores predisponentes associados a essa neoplasia, a exposição à radiação solar é apontada como um dos mais importantes (Naik et al., 1969; Naik et al., 1970). Levantamento realizado na Índia revelou que pouco mais de $1 \%$ dos casos eram bilaterais (Naik et al., 1969); a grande maioria dos tumores apresenta-se unilateralmente e em machos castrados (Kulkarni, 1953; Zubaidy, 1976).

No Brasil, há alguns relatos sobre CEBC unilateral em vacas adultas (Rezende e Neves, 1975; Gomes et al., 2012; Fernandes et al., 2017), mas não bilateral. Alguns pesquisadores acreditam que a significativa maior ocorrência dos CEBC em machos castrados deva-se à modificação hormonal decorrente da castração (Lall, 1953; Naik et al., 1969). Naik et al. (1970) discutem o papel da castração e a influência hormonal no carcinoma da base do chifre, a partir de um relato de caso de um bovino com criptorquidismo bilateral de cinco anos. A hipótese levantada pelos autores seria que os testículos ectópicos poderiam produzir uma quantidade insuficiente de hormônios masculinos, levando à hiperplasia de células intersticiais, decorrente de um efeito compensatório fisiológico, de forma semelhante ao que ocorre na castração.

Acredita-se que, no Brasil, pelo fato de os machos castrados serem abatidos mais precocemente, a ocorrência dessa neoplasia seja baixa. Por outro lado, com os cruzamentos zebuínos e a produção leiteira, é possível notar essa lesão em fêmeas, devido à longevidade e à permanência desses animais no sistema de produção. Neste relato, ocorreu um caso esporádico, ou seja, a permanência de uma matriz de corte em anestro em um rebanho comercial por muitos anos. É possível que o desequilíbrio hormonal e a idade avançada do animal tenham sido importantes fatores predisponentes no presente caso. Essa vaca apresentou histórico de apenas uma prenhez e muitos anos de anestro, sem nenhum tratamento hormonal, além de alterações na dosagem hormonal e um cisto na adeno-hipófise.

Apenas em um relato de ocorrência CEBC em uma vaca, mencionam-se informações do histórico reprodutivo; o animal seria uma doadora de embriões, mas não foi feita correlação dessa condição como possível fator predisponente à neoplasia (Fernandes et al., 2017). Embora a relação entre $\mathrm{CEBC}$ e alterações hormonais seja provável, mais estudos são necessários para esclarecer a patogênese do CEBC.

\section{CONCLUSÃO}

Relata-se a ocorrência de um carcinoma espinocelular bilateral da base do chifre em uma vaca, condição aparentemente ainda não descrita na literatura, porém não foi possível comprovar o envolvimento hormonal na patogênese da doença.

\section{REFERÊNCIAS}

FERNANDES, T.R.R.; ARAÚJO, A.L.; CASAGRANDE, F.P. et al. Carcinoma de células escamosas na base do chifre com metástase pulmonar em um bovino: relato de caso. Braz. J. Vet. Med., v.39, p.208-214, 2017.

FIRMINO, M.O.; OLIVEIRA, A.M.; ALVES, R.C. et al. Carcinoma de células escamosas diagnosticados em bovinos no sertão da Paraíba. Rev. Acad. Ciênc. Anim., v.15, p.85-86, 2017.

GOMES, R.G.; RAFAEL, L.A.; HEADLEY, S.A.; SAMPAIO, A.J.S.A. Aspectos clínicos e histopatológicos do carcinoma da base do chifre em uma vaca Nelore - relato de caso. Semin. Ciênc. Agrár., v.33, p.1931-1936, 2012.

KULKARNI, H.V. Carcinoma of the horn in bovines of the old Baroda State. Indian Vet. J., v.29, p.415-421, 1953.

LALL, H. K. Incidence of horn cancer in Meerut circle, Uttar Pradesh. Indian Vet. J., v.30, p.205209, 1953.

LEMOS, R.A.A.; NAKAZATO, L.; BARROS, C.S.L. Carcinoma da base do chifre. In: LEMOS, R.A.A. (Eds.). Principais enfermidades de bovinos de corte do Mato Grosso do Sul. Campo Grande: Universidade Federal do Mato grosso do Sul, 1998. p.497-498. 
NAIK, S.N.; BALAKRISHNAN， C.R.; RANDELIA, H.P. Epidemiology of horn cancer in Indian Zebu cattle: breed incidence. Br. Vet. J., v.125, p.222-230, 1969.

NAIK, S.N.; RANDELIA, H.P.; DABHOLKAR, R.D. Carcinoma of the horn in a cryptorchidbull. Pathol. Vet., v.7, p.265-269, 1970.

NASCIMENTO, E.F.; SILVA, J.M.L.; LÚCIO, W.F.; MELLO, M.A. Carcinoma espino-celular de base de chifre em bovinos. Arq. Esc. Vet., v.27, p.39-43, 1975.
REZENDE, A.M.L.; NEVES, P.T. Carcinoma do chifre em zebuíno importado. Pesqui. Agropecu. Bras., v.10, p.41-44, 1975.

ZUBAIDY, Ali J. Horn cancer in cattle in Iraq. Vet. Pathol., v.13, p.453-454, 1976. 